\title{
Are Steroids a Beneficial Adjunctive Therapy in the Immunosuppressed Patient with Herpes Simplex Virus Encephalitis?
}

\author{
Karlo J. Lizarraga Lucien C. Alexandre Ciro Ramos-Estebanez \\ Amedeo Merenda \\ Neurocritical Care Division, Department of Neurology, Miller School of Medicine, \\ University of Miami, Miami, Fla., USA
}

\section{Key Words}

Herpes simplex virus encephalitis · Immunosuppression · Corticosteroids

\begin{abstract}
Few reports describe the reactivation of latent herpes simplex virus causing encephalitis (HSVE) in patients undergoing brain radiation therapy and a concomitant steroid regimen. The role for steroid use in the treatment of patients with HSVE has not been fully elucidated. We report the case of a female patient immunosuppressed by steroids and brain radiation who developed HSVE and responded to acyclovir and dexamethasone.
\end{abstract}

\section{Introduction}

Herpes simplex virus (HSV) is the most common cause of sporadic encephalitis in humans [1]. HSV encephalitis (HSVE) may be caused by a primary infection or reactivation of a latent infection of sensory ganglia or frontotemporal cortices. HSV reactivation from the trigeminal ganglion or brain parenchyma might be caused by immunosuppression due to the concomitant use of corticosteroids and brain radiotherapy [2].

Typical HSVE presentation includes a rapid onset of fever and impaired consciousness, often accompanied by focal neurologic signs and seizures. Acyclovir is the treatment of choice for it significantly reduces mortality. Unfortunately, complete recovery occurs only in half of the patients [3]. We report a case in which the adjunctive use of steroids lead to a significant improvement in an immunosuppressed patient with HSVE. 


\section{Clinical Presentation}

A 32-year-old, right-handed, female patient with a right glomus jugulare paraganglioma was undergoing stereotactic radiation therapy (including the trigeminal ganglion in Meckel's cave) (fig. 1) and received oral dexamethasone (16 mg daily). After completing an 11-week regimen, dexamethasone was tapered off and discontinued.

The following week, she began having emotional lability and difficulties with short-term memory. For the next 3 weeks, her family noted increased irritability, difficulty in following commands and focusing on tasks. Eventually, she was febrile and had a 5-min episode characterized by the inability to answer simple questions, lip smacking, chewing and wringing of the bed sheets.

Once admitted, she was awake, alert and only oriented to person. She followed axial and appendicular commands. Stereotyped movements of her hands and mouth were noted. Examination revealed that the cranial motor nerves were intact, and there were no meningeal signs. A CT scan showed a new focal hypodensity within the right temporal lobe (fig. 2a), but the paraganglioma remained unchanged. Empirical levetiracetam, vancomycin, cefepime, ampicillin and acyclovir were started. Lumbar puncture showed 120 lymphocytes $/ \mathrm{mm}^{3}$, a glucose level of $52 \mathrm{mg} \%$ and a protein level of $115 \mathrm{mg} \%$. Gram stain was negative but HSV-1 PCR of her cerebrospinal fluid returned positive.

The next day, she became lethargic, and electroencephalography showed generalized background delta slowing. An MRI scan demonstrated bilateral restricted diffusion, a high FLAIR signal and T1 postcontrast enhancement in her mesial temporal, orbitofrontal, cingular and insular lobes.

Until the fifth day after admission, the patient remained febrile and could not follow commands. A CT scan showed larger bilateral hypodensities in the orbital frontal, temporal, insular and cingular regions (fig. 2b). Daily dexamethasone $40 \mathrm{mg}$ iv was added to her acyclovir regimen.

Seventy-two hours later, the patient was afebrile and followed axial commands. Once she had completed 5 days of steroid and 21 days of acyclovir treatment, she was alert, oriented to person and place, following axial and appendicular commands and producing simple sentences.

\section{Discussion}

Clinicians are hesitant to use steroids during HSVE due to the concern of immunosuppression. Indeed, several observations argue for a reactivation of latent HSV in patients receiving radiation and corticosteroids, leading to HSVE [2]. Furthermore, the morbidity of HSV has mostly been associated with its reactivation, which is enhanced by a steroidimpaired immunological response [4]. However, this evidence stems from nonneural culture and tissue studies. Besides, animal experiments showed that steroid therapy does not correlate with HSV dissemination or viral load [5]. Finally, even if the viral load were enhanced by steroid therapy, other quantitative viral markers do not correlate with radiological changes [6] or clinical outcomes [7].

Corticosteroids may be beneficial in HSVE for decreasing the activation of several inflammatory pathways [8]. Actually, adjunctive corticosteroid administration has been advantageous in the treatment of other infectious diseases with exaggerated inflammatory responses (i.e. bacterial meningitis [9], tuberculous meningitis [10] or herpetic keratitis [11]). In the case of HSVE, animal models [5, 8] and human reports [12] support the 
adjunctive use of corticosteroids. Steroids are used in HSVE mostly when there is evidence of progression in spite of acyclovir treatment (fig. 2) [12]. We hope that the GACHE trial [13] will address the value of corticosteroids in HSVE.

\section{References}

1 Raschilas F, Wolff M, Delatour F, et al: Outcome of and prognostic factors for herpes simplex encephalitis in adult patients: results of a multicenter study. Clin Infect Dis 2002;35:254-260.

$\checkmark 2$ Jacobs DH: Herpes simplex virus encephalitis following corticosteroids and cranial irradiation. Neurology 1999;52:1108-1109.

-3 McGrath N, Anderson NE, Croxson MC, Powell KF: Herpes simplex encephalitis treated with acyclovir: diagnosis and long term outcome. J Neurol Neurosurg Psychiatry 1997;63:321-326.

4 Harrell AJ, Sydiskis RH: The effect of dexamethasone on the replication of herpes simplex virus in human gingival fibroblast cultures. J Baltimore Coll Dent Surg 1982;35:9-13.

-5 Thompson KA, Blessing WW, Wesselingh SL: Herpes simplex replication and dissemination is not increased by corticosteroid treatment in a rat model of focal Herpes encephalitis. J Neurovirol 2000;6:25-32.

-6 Meyding-Lamadé UK, Lamadé WR, Wildemann BT, et al: Herpes simplex virus encephalitis: chronic progressive cerebral magnetic resonance imaging abnormalities in patients despite good clinical recovery. Clin Infect Dis 1999;28:148-149.

-7 Wildemann B, Ehrhart K, Storch-Hagenlocher B, et al: Quantitation of herpes simplex virus type 1 DNA in cells of cerebrospinal fluid of patients with herpes simplex virus encephalitis. Neurology 1997;48:13411346.

8 Sellner J, Dvorak F, Zhou Y, et al: Acute and long-term alteration of chemokine mRNA expression after antiviral and anti-inflammatory treatment in herpes simplex virus encephalitis. Neurosci Lett 2005;374:197202.

-9 de Gans J, van de Beek D; European Dexamethasone in Adulthood Bacterial Meningitis Study Investigators: Dexamethasone in adults with bacterial meningitis. N Engl J Med 2002;347:1549-1556.

10 Thwaites GE, Nguyen DB, Nguyen HD, et al: Dexamethasone for the treatment of tuberculous meningitis in adolescents and adults. N Engl J Med 2004;351:1741-1751.

$\checkmark 11$ Wilhelmus KR, Gee L, Hauck WW, et al: Herpetic Eye Disease Study. A controlled trial of topical corticosteroids for herpes simplex stromal keratitis. Ophthalmology 1994;101:1883-1896.

-12 Kamei S, Sekizawa T, Shiota H, et al: Evaluation of combination therapy using aciclovir and corticosteroid in adult patients with herpes simplex virus encephalitis. J Neurol Neurosurg Psychiatry 2005;76:1544-1549.

13 Martinez-Torres F, Menon S, Pristch M, et al, GACHE Investigators: Protocol for German trial of Acyclovir and corticosteroids in Herpes-simplex-virus-encephalitis (GACHE): a multicenter, multinational, randomized, double-blind, placebo-controlled German, Austrian and Dutch trial [ISRCTN45122933]. BMC Neurol 2008;8:40. 


\section{Case Reports in Neurology}

\begin{tabular}{l|l}
\hline Case Rep Neurol 2013;5:52-55 & \\
\hline DOI: $\underline{10.1159 / 000350572}$ & $\begin{array}{l}\text { @ 2013 S. Karger AG, Basel } \\
\text { www.karger.com/crn }\end{array}$ \\
\hline
\end{tabular}

Lizarraga et al.: Are Steroids a Beneficial Adjunctive Therapy in the Immunosuppressed Patient with Herpes Simplex Virus Encephalitis?

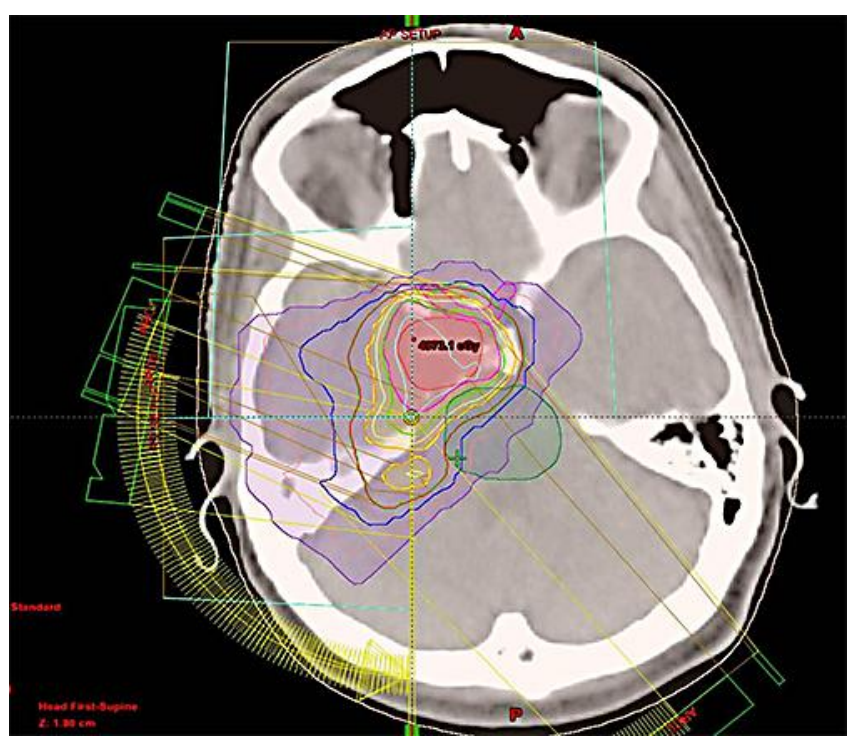

Fig. 1. The patient's radiation therapy plan involving the left trigeminal ganglion (Meckel's cave), frontal and temporal cortices.
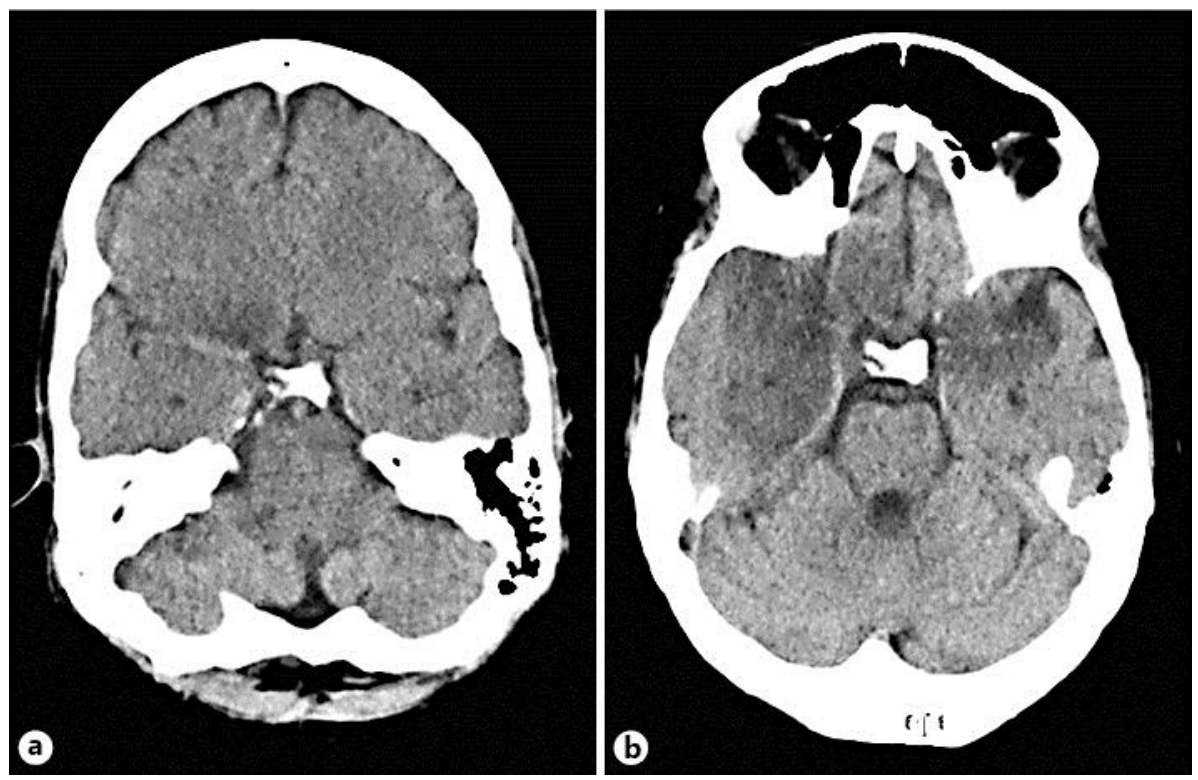

Fig. 2. Head CT, axial view. a A focal hypodensity within the right temporal lobe is observed on admission. b On the fifth day after admission, bilateral worsening of the hypodensities in the orbital frontal, cingular, insular and temporal regions in spite of isolated acyclovir treatment occurred. 